\title{
Immune mediated mechanism for thrombosis: antiphospholipid antibody binding to platelet membranes*
}

\author{
MUNTHER A KHAMASHTA, ${ }^{1}$ E NIGEL HARRIS, \\ AZZUDIN E GHARAVI, ${ }^{3}$ GENEVIEVE DERUE, ${ }^{\prime}$ ANTONIO GIL ${ }^{4}$ \\ JUAN JOSE VÁZQUEZ, ${ }^{4}$ AND GRAHAM R V HUGHES ${ }^{1}$
}

From the ${ }^{1}$ Lupus Research Laboratory, The Rayne Institute, St Thomas's Hospital, London, UK; the ${ }^{2}$ Rheumatology Division, Department of Medicine, University of Louisville, Kentucky, USA; the ${ }^{3}$ Hospital for Special Surgery, Cornell University, New York, USA; and ${ }^{4}$ La Paz Hospital, Madrid, Spain

SUMMARY Because thrombocytopenia occurs frequently in patients with anticardiolipin (aCL) antibodies and thrombosis, some investigators have proposed that aCL antibodies may play a direct part in thrombosis by binding and activating platelets. To test this proposal experiments were performed to determine whether aCL antibodies can bind platelets. Preincubation of aCL positive sera with freeze-thawed platelets caused significant inhibition of aCL activity in four serum samples tested. Antibodies with cardiolipin binding activity were subsequently eluted from these platelets. Total phospholipids extracted from platelets inhibited aCL activity, and the specific phospholipids bound were shown to be phosphatidylethanolamine, phosphatidylserine, and phosphatidylinositol. It is concluded that $\mathrm{aCL}$ antibodies can bind phospholipids in platelet membranes but pertubation of the membrane must first occur.

Key words: thrombocytopenia, lupus anticoagulant, anticardiolipin antibody.

Recent studies suggest that antiphospholipid (aPL) antibodies are associated with repeated episodes of venous or arterial thrombosis, or both, recurrent fetal loss, and thrombocytopenia. ${ }^{1-3}$ Although the clinical association is strong, little is known of the mechanisms whereby the presence of aPL antibodies results in thrombosis.

As the phospholipid membrane of platelets has a role in the thrombotic process ${ }^{4}$ it has been proposed that aPL antibodies may bind platelet membranes, so causing their activation, aggregation, and thrombosis. ${ }^{15}$ The occurrence of thrombocytopenia in some affected patients has also led to suggestions that aPL antibodies may directly mediate platelet destruction. $^{5}$

The aims of this study were to determine whether

Accepted for publication 19 May 1988.

Correspondence to Dr Munther A Khamashta, Lupus Research Laboratory, The Rayne Institute, St Thomas's Hospital, London SE1 7EH, UK.

*These data were presented in part at the American Rheumatism Association meeting in Washington DC, USA, June 1987.
aPL antibodies can bind platelets in vitro and to identify the components of the platelet membranes bound by these antibodies.

\section{Patients and methods}

PATIENTS

Serum samples from four patients with high aCL antibody levels were selected for study. Two of these four patients fulfilled the revised American Rheumatism Association criteria for systemic lupus erythematosus, ${ }^{6}$ and two were classified as having the 'antiphospholipid syndrome', ${ }^{8}$ Three of the four patients had a history of thrombosis, two had thrombocytopenia (platelet count $<100 \times 10^{9} / 1$ ), and three had a positive Coombs' test. All four patients had a positive lupus anticoagulant test. One patient had IgG aCL antibodies, one patient IgM, and the remaining two patients had both IgG and IgM aCL antibodies.

\footnotetext{
PREPARATION OF PLATELETS AND

ER Y T H R O C Y T E S
}

Recently expired units of platelet concentrates 
collected in citrate phosphate dextrose (CPD) adenine 1 and units of whole blood collected in CPD anticoagulant were used for study.

Twenty millilitre aliquots of platelet concentrates were centrifuged at $1500 \mathrm{~g}$ for 20 minutes at room temperature. The supernatant was discarded and the pellets were washed three times in phosphate buffered saline (PBS) $\mathrm{pH} 7.4$ by centrifugation at $1500 \mathrm{~g}$ for 10 minutes each time. The washing procedure was monitored by light microscopy. The final platelet preparations did not contain more than one erythrocyte or leucocyte per 50 high power fields.

Twenty millilitre aliquots from a whole blood sample were centrifuged at $300 \mathrm{~g}$ for 20 minutes, following which the superhatant plasma, leucocyte, and platelet layers were removed and discarded. The red cells were then washed three times by suspension in PBS.

The final concentrations of platelets and erythrocytes were estimated by Coulter Counter model S-plus IV and adjusted to $2 \times 10^{9} / \mathrm{ml}$. The washed platelets and erthrocytes were stored in small aliquots $(1 \mathrm{ml})$ at $-20^{\circ} \mathrm{C}$ until further use. Partially disrupted platelets and erythrocytes were obtained by freeze-thawing three times. Sonicated platelets were prepared by sonicating twice with a Soniprep 150 (MSE) sonicator, on ice, for three minutes each time with one minute intervals.

\section{ISOLATION OF aCL ANTIBODIES USING PLATELETS}

Ten millilitre aliquots of serum with high aCL binding activity were mixed with $5 \mathrm{ml}$ of freezethawed platelets prepared as described previously. The mixture was incubated at $37^{\circ} \mathrm{C}$ for one hour and overnight at room temperature with constant mixing. The mixture was then centrifuged at 25000 $g$ for one hour and the supernatant removed. The pellet was resuspended in $10 \mathrm{ml}$ of PBS and thoroughly washed. The mixture was again centrifuged at $25000 \mathrm{~g}$ for 30 minutes and the supernatant removed. This washing procedure was repeated three times. After the third wash the pellet was resuspended in $2 \mathrm{ml}$ of $1.5 \mathrm{M}$ potassium iodide and incubated for one hour with constant mixing to elute antibodies bound to platelet membranes. The preparation was centrifuged at $25000 \mathrm{~g}$ for 15 minutes and the pellet discarded. Five millilitres of chloroform was added to the supernatant, vortex mixed, allowed to stand for 10 minutes at room temperature, then centrifuged at $1500 \mathrm{~g}$ for 20 minutes. On this occasion the upper aqueous layer was carefully removed and dialysed overnight against PBS at $4^{\circ} \mathrm{C}$. The final preparation was stored at $-20^{\circ} \mathrm{C}$ until ready for use. This preparation was characterised by double immunodiffusion
(Ouchterlony technique) using antisera to human? IgG, IgM, IgA, and human serum albumin ( $\operatorname{Sig}_{\sigma}$ ma Chemical Company, UK) and by immuno: electrophoresis using anti-whole human serume (Sigma Chemical Company, UK). The isolate $\Phi$ preparation was also tested for $\mathrm{aCL}$ bindin activity by an enzyme linked immunosorbent assasf (ELISA).

EXTRACTION OF PLATELET LIPIDS
Lipids were extracted from platelets according to the method outlined by Bligh and Dyer. ${ }^{9}$

THIN LAYER CHROMATOGRAPHY

Platelet phospholipids were separated using high performance thin layer chromatography plates (HPTLC precoated silica gel $\mathrm{F}_{254} 10 \times 10 \mathrm{~cm} \Phi$ purchased from Merck (Darmstadt, W Germany) The plate was developed in a solvent system containing chloroform:methanol:13.5 N ammonia? water $(70: 30: 4: 1, v / v) .^{10}$ Platelet phospholipids wer $\overrightarrow{8}$ identified by comparison with pure reference compounds (Sigma Chemical Company, UK). The्ष platelet phospholipids separated on HPTLC plate were re-extracted with chloroform:methanol. Aftb aliquot of each of the re-extracted phospholipids: was rerun on HPTLC plates with appropriate reference compounds to confirm the purity of extract and its identity. The remaining portions of the re-extracted phospholipids were used to prepare liposomes for inhibition studies. ${ }^{11} 12$

AN TICARDIOLIPIN ELISA

Anticardiolipin activity was determined by the ELISA technique described by Gharavi et al. ${ }^{13}$

ANTITETANUS ELISA

Polyvinyl chloride plates (Flow Laboratories, UK承 were coated with $50 \mu \mathrm{l} /$ well of highly purified tetanus toxoid diluted in PBS at a concentration of $1 / 50$. The plates were then placed in a chamber and incubated for one hour at $37^{\circ} \mathrm{C}$ and overnight at $4^{\circ} \mathrm{C}_{\odot}$ Antitetanus activity was determined by a protoco similar to that used for the aCL antibody. ${ }^{13}$

INHIBITION STUDIES

Inhibition studies of antibody to cardiolipin coated ELISA plates were performed by preincubating serum at $50 \%$ maximum binding activity wit platelets, erythrocytes, or phospholipid liposomes $37^{\circ} \mathrm{C}$ for one hour and overnight at roor temperature, with constant mixing. Control samples were prepared by preincubating each serum at $50 \%$ activity with PBS under conditions described above The percentage inhibition was calculated by the following equation: 
$\%$ Inhibition $=$ OD control sample - OD inhibited sample $\times$ OD control sample

where OD is the optical density.

\section{Results}

INHIBITION OF CARDIOLIPIN BINDING ACTIVITY BY PLATELETS AND

ER Y T H R O CYTES

Preincubation of the four aCL positive sera with intact platelets caused little inhibition of cardiolipin binding activity. On the other hand, preincubation of these sera with freeze-thawed or sonicated platelets caused significant inhibition of cardiolipin binding activity. It was found too, that preincubation of the four aCL positive sera with freezethawed erythrocytes also caused marked inhibition of cardiolipin binding activity, but there was no inhibition by intact erythrocytes (Fig. 1). Freezethawed platelets caused no inhibition of binding activity of the positive antitetanus serum used as control (Fig. 2).

\section{ÁNTIBODY ELUTED FROM PLATELET MEM B R A N ES}

A second series of experiments (see 'Patients and methods') was performed to demonstrate aCL binding to platelets. Essentially, each of the four

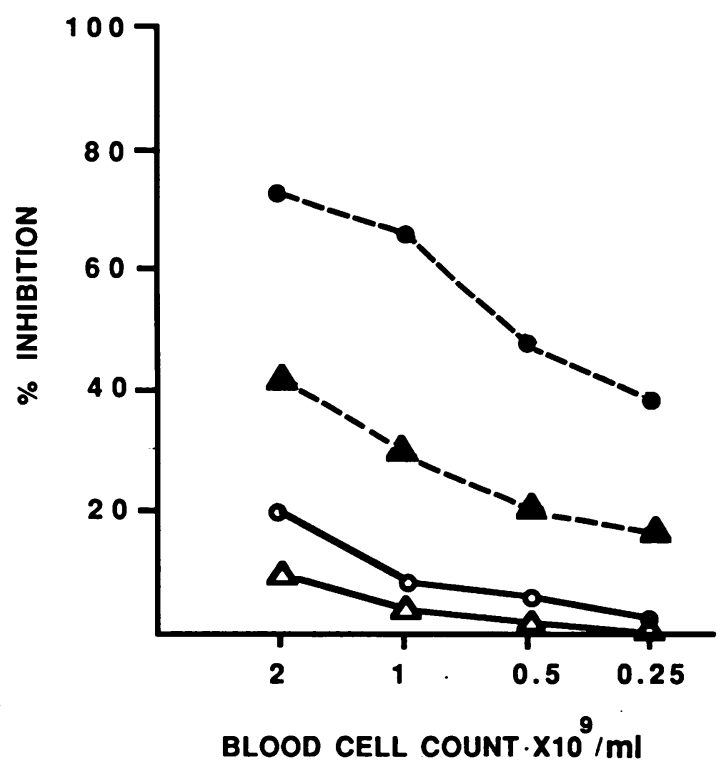

Fig. 1 Inhibition of IgM anticardiolipin activity in one serum by varying concentrations of freeze thawed $(O)$ and intact $(O)$ platelets and freeze-thawed $(\Delta)$ and intact $(\Delta)$ erythrocytes. serum samples studied was incubated with freezethawed platelets and antibodies bound to platelets eluted by potassium iodide.

All four eluted preparations contained immunoglobulins. In every instance the predominant isotype of the eluted preparation corresponded to the aCL antibody isotype of the serum from which the preparation was obtained. Thus platelet eluates from the serum of the patient with IgG aCL activity alone contained immunoglobulins only of IgG isotype (Fig. 3). The eluate obtained from the serum of the patients with IgM aCL activity had only IgM,

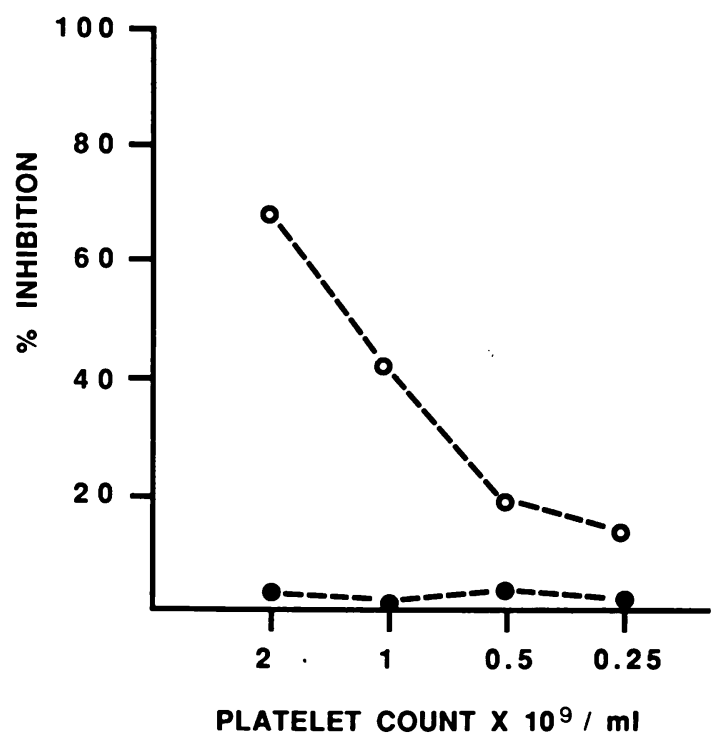

Fig. 2 Inhibition of IgG anticardiolipin activity $(O)$ and of IgG antitetanus activity (O) by varying concentrations of freeze-thawed platelets.

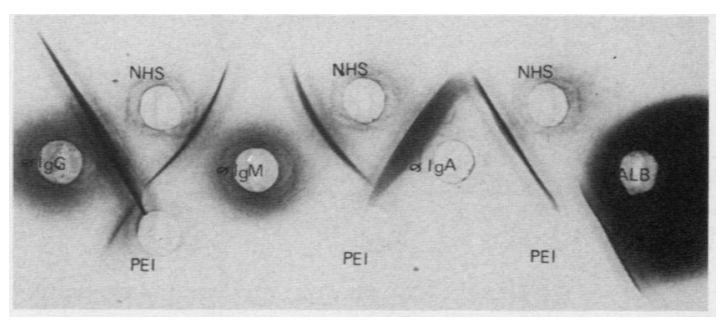

Fig. 3 Ouchterlony pattern of immunoglobulins eluted from platelets (PEI) after preincubation with patient serum. The patient serum had only IgG aCL activity and after preincubation with platelets only immunoglobulins of the IgG isotype were eluted. Normal human serum (NHS) was used as control. $A L B=$ albumin. 
and the eluates from the two serum samples with IgG and IgM aCL activities had both IgG and IgM immunoglobulins. Eluted preparations from platelets also contained significant quantities of albumin. Each of the four eluted preparations had cardiolipin binding activity and the binding activity of each preparation was confined to the same isotype as that of the serum from which the preparation was obtained.

IDENTIFICATION OF COMPONENTS OF PLATELET MEMBRANE BOUND BY aCL ANTIBODIES

Two aCL positive sera were preincubated with total phospholipids extracted from platelets and inhibition of cardiolipin binding activity determined. In both instances total platelet phospholipids inhibited cardiolipin binding activity to an extent similar to that observed using freeze thawed platelets.

The total platelet phospholipid extract was

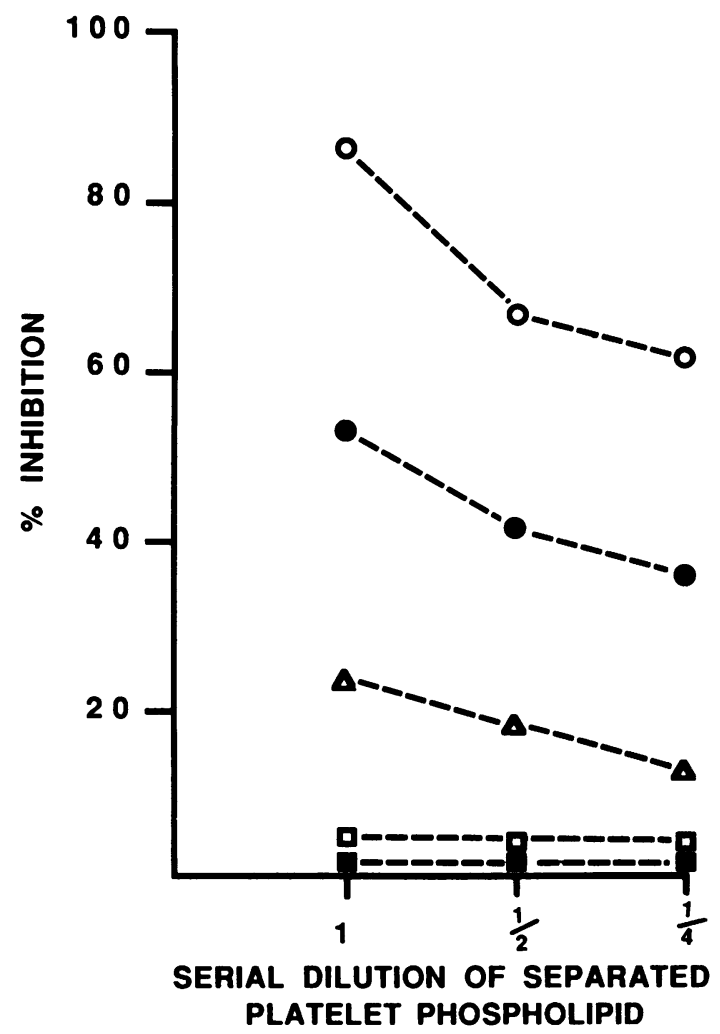

Fig. 4 Inhibition of IgM anticardiolipin activity in one serum by individual phospholipids extracted from platelets. $\mathrm{O}=$ phosphatidylethanolamine; $\bigcirc=$ phosphatidylserine:

$\triangle=$ phosphatidylinositol; $\square=$ sphingomyelin;

= phosphatidylcholine. separated into its individual components by HPTLC and inhibition of cardiolipin binding activity by eactor. of the separated components examined. The phospholipid components identified were phospha⿳⺈ tidylethanolamine (PE), sphingomyelin (SPH) phosphatidylcholine (PC), phosphatidylserine (PS)울 and phosphatidylinositol (PI). PE, PS, and PI alf inhibited cardiolipin binding activity, but SPH an PC caused little or no inhibition (Fig. 4). It wa\& noteworthy that although the extracted platelet phospholipid identified as PE caused most marked inhibition of cardiolipin binding activity, a simila $\vec{\omega}$ preparation obtained commercially and with the same $R_{f}$ value on HPTLC plates did not inhibi产 cardiolipin binding activity.

\section{Discussion}

Recent studies have shown that patients with higho levels of aPL antibodies have an increased risk for venous or arterial thrombosis or both. ${ }^{14}{ }^{15}$ Because some of these patients also have episodes of thrombocytopenia, ${ }^{5}$ and because platelets have aro important role in the clotting process, ${ }^{16}$ we have proposed that aPL antibodies may bind platejeto membrane phospholipids so causing their activation aggregation, and thrombosis. ${ }^{15}$ On the other hamd it may be argued that platelet phospholipids are accessible to aPL antibodies, either because of sterie hindrance by platelet membrane glycoproteins, ${ }^{17}$ oํㅐ because anionic phospholipids (PS, PI) bound bo aCL antibodies ${ }^{11} 12$ are located on the inner leafle? of the lipid bimolecular membrane away from the extracellular milieu. ${ }^{16}$

The present study was designed to determine whether aCL antibodies bind platelet membranes: and to identify the membrane components bound bo these antibodies. We found that preincubation of aCL positive sera with 'intact' platelets caused little inhibition of cardiolipin binding activity, buif preincubation with freeze-thawed or sonicate platelets resulted in greater than $50 \%$ inhibition of cardiolipin binding activity. Similar results wer? obtained with intact and freeze-thawed red bloow cells. The similarity between results obtained witt platelets and with red cells may be explained by the fact that the composition and probably the distrin bution of phospholipids in platelet and red blood cell membranes are similar. ${ }^{10}$ Hence freeze-thawing probably results in exposure in both types of cells of phospholipids that can be bound by aCL antibodies? As far as is known, however, only platelet memos branes undergo molecular rearrangements during the clotting process, ${ }^{4}$ therefore the present stud was confined to platelets.

The observed inhibition of aCL activity by freeze्ष户 
thawed platelets might have occurred because these immunoglobulins might have become attached to platelet membranes non-specifically or by $F_{c}$ receptors. Two experiments excluded this possibility. Firstly, preincubation of an antitetanus positive serum with freeze-thawed platelets caused little or no inhibition of antitetanus activity. Secondly, when serum samples with high cardiolipin binding activity were preincubated with platelets, immunoglobulins with $\mathrm{aCL}$ activity were eluted from these platelets. In addition, the eluted antibodies were restricted to the same isotype as that of the aCL positive sera. If binding were non-specific then one might have expected that both IgG and IgM immunoglobulins would have been eluted from platelet membranes in all serum samples tested. On the other hand, if binding occurred via $F_{c}$ receptors then only IgG should have been eluted.

This study showed that it is the lipid component of the platelet membrane that is bound by $\mathrm{aCL}$ antibodies as demonstrated by the fact that $\mathrm{aCL}$ activity was inhibited by total phospholipids extracted from platelets to an extent similar to that obtained with freeze-thawed platelets. The zwitterionic phospholipids PC and SPH were not bound by aCL antibodies. PC and SPH are the main phospholipids located on the outer leaflet of the bimolecular membrane and this may explain why aCL antibodies may not bind intact platelets. The anionic phospholipids PS and PI as well as the zwitterionic PE were bound by aCL antibodies. Of interest is the fact that all three platelet phospholipids bound by $\mathrm{aCL}$ antibodies are located primarily on the inner leaflet of the bimolecular lipid membrane ${ }^{416}$ and presumably become exposed and accessible to aCL antibodies by freeze thawing. Anticardiolipin binding to platelet PE was unexpected. We have found previously, and confirmed in the present series of experiments, that preincubation of aCL positive sera with commercially obtained PE (bovine brain) does not result in inhibition of cardiolipin binding activity. ${ }^{11}$ It is possible that there may be subtle differences in the conformation of individual phospholipid molecules depending on their source and on the phospholipids with which they are mixed. ${ }^{18} 19$ Recently, Rauch and colleagues using a monoclonal aPL antibody with lupus anticoagulant activity found that this antibody bound PE in one configuration but not another. ${ }^{20}$

It is well known that the lupus anticoagulant test can be 'bypassed' by addition of freeze-thawed or sonicated platelets, but the mechanism of this bypass phenomenon is not established. ${ }^{21} 22$ One possibility is that the sonicated platelets provide an additional phospholipid template on which the prothrombin activator complex can form and this would enable bypass of the lupus anticoagulant activity, whatever the mechanism that accounts for this activity. An alternative explanation is that platelet membrane phospholipids exposed on sonication absorb aPL antibodies, so preventing these antibodies from blocking the prothrombin activator complex-phospholipid interaction. The findings of the present series of experiments show that the neutralisation reaction probably occurs because of the latter mechanism whereby aPL antibodies are absorbed out of plasma by platelet phospholipids.

The absence of binding of aPL antibodies to intact platelets in this study confirms a number of abstracted studies which show that lupus anticoagulant or aCL positive plasma have no effect on platelet function. ${ }^{23}$ On the other hand, demonstration of binding to sonicated platelets suggests that if aPL antibodies cause thrombosis through a platelet mediated mechanism one must propose that partial activation of the platelet and exposure of target phospholipids must take place before antibody binding. Hence, owing to the observations reported here, we are currently performing experiments in our laboratories using partially activated rather than inactivated platelets.

We thank Dr K L I Rogers and Ms P Tannenbaum of the South London Transfusion Centre for the donation of blood cells and $\mathrm{Mr}$ Thomas Patterson for technical assistance. This work was supported by grants from the British SLE Aid Group and by the Arthritis and Rheumatism Council.

\section{References}

1 Harris E N, Gharavi A E, Hughes G R V. Anti-phospholipid antibodies. Clin Rheum Dis 1985; 11: 591-609.

2 Vermylen J, Blockmans D, Spitz B, Deckmyn H. Thrombosis and immune disorders. Clin Haematol 1986; 15: 393-412.

3 Hughes G R V. Thrombosis, abortion, cerebral disease, and the lupus anticoagulant. $\mathrm{Br}$ Med $J$ 1983; 287: 1088-9.

4 Schick P K, Kurica K B, Chacko G K. Location of phosphatidyl ethanolamine and phosphatidyl serine in the human platelet plasma membrane. J Clin Invest 1976; 57: 1221-6.

5 Harris E N, Asherson R A, Gharavi A E, Morgan S H, Derue G, Hughes G R V. Thrombocytopenia in SLE and related autoimmune disorders: association with anticardiolipin antibodies. Br J Haematol 1985; 59: 227-30.

6 Tan E M, Cohen A S, Fries J F, et al. The 1982 revised criteria for the classification of systemic lupus erythematosus. Arthritis Rheum 1982; 25: 1271-7.

7 Hughes G R V, Harris E N, Gharavi A E. The anticardiolipin syndrome. $J$ Rheumatol 1986; 13: 486-9.

8 Harris E N. Syndrome of the black swan. Br J Rheumatol 1987; 26: 324-6.

9 Bligh E G, Dyer W J. A rapid method of total lipid extraction and purification. Canadian Journal of Biochemistry and Physiology 1959; 37: 911-7.

10 Cohen P, Derksen A. Comparison of phospholipid and fatty acid composition of human erythrocytes and platelets. $\mathrm{Br} J$ Haematol 1969; 17: 359-71.

11 Harris E N, Gharavi A E, Loizou S, et al. Crossreactivity of antiphospholipid antibodies. J Clin Lab Immunol 1985; 16: 1-6. 
12 Harris E N, Gharavi A E, Tincani A, et al. Affinity purified anti-cardiolipin and anti-DNA antibodies. J Clin Lab Immunol 1985; 17: 155-62.

13 Gharavi A E, Harris EN, Asherson R A, Hughes G R V. Anticardiolipin antibodies: isotype distribution and phospholipid specificity. Ann Rheum Dis 1987; 46: 1-6.

14 Harris E N, Chan J K H, Asherson R A, Aber V R, Gharavi A E, Hughes G R V. Thrombosis, recurrent fetal loss, and thrombocytopenia. Predictive value of the anticardiolipin antibody test. Arch Intern Med 1986; 146: 2153-6.

15 Lockshin M D, Druzin M L, Goei S, et al. Antibody to cardiolipin as a predictor of fetal distress or death in pregnant patients with systemic lupus erythematosus. N Engl J Med 1985; 313: $152-6$.

16 Marcus A J, Ullman H L, Safier L B. Lipid composition of subcellular particles of human platelets. $J$ Lipid Res 1969; 10: 108-14.

17 Thiagarajan P, Shapiro S S, DeMarco L. Monoclonal immunoglobulin $\mathbf{M}$ coagulation inhibitor with phospholipid specificity-mechanism of a lupus anticoagulant. J Clin Invest 1980; 66: 397-405.
18 Alving C R. Antibodies to liposomes, phospholipids and phosphate esters. Chem Phys Lipids 1986; 40: 303-14.

19 Lockshin M D. Anticardiolipin antibody. Arthritis Rheum1987; 30: 471-2.

20 Rauch J, Tannebaum M, Tannebaum $\mathrm{H}$, et al. Human hybridoma lupus anticoagulant distinguish between lamellarc and hexagonal phase lipid system. J Biol Chem 1986; 261: 9672-7.

21 Howard M A, Firkin B G. Investigations of the lupus-like inhibitor by-passing activity of platelets. Thromb Haemost 1983 50: 775-9.

22 Triplett D A, Brandt J T, Kaczor D, Schaeffer J. Laborator diagnosis of lupus inhibitors: a comparison of the tissue. thromboplastin inhibition procedure with a new platelet neutralization procedure. Am J Clin Pathol 1983; 79: 678-82.

23 Derksen R H W M, Hasselaar P, Blokzijl L, de Groot Ph G. Thrombosis associated with antiphospholipid antibodies cannot be explained by effects on endothelial and platelet prostanoid synthesis. Proceeding of the IIIrd International symposium on-V antiphospholipid antibodies. Kingston, Jamaica, 1988. Clinical $\vec{\circ}$ and Experimental Rheumatology Supplement (in press). 